\title{
Nursing home characteristics associated with methicillin-resistant Staphylococcus aureus (MRSA) Burden and Transmission
}

\author{
Courtney R Murphy ${ }^{1 *}$, Victor Quan ${ }^{1}$, Diane Kim, Ellena Peterson², Matthew Whealon ${ }^{1}$, Grace Tan², Kaye Evans²,
} Hildy Meyers ${ }^{3}$, Michele Cheung ${ }^{3}$, Bruce Y Lee ${ }^{4}$, Dana B Mukamel ${ }^{5}$ and Susan S Huang ${ }^{1}$

\begin{abstract}
Background: MRSA prevalence in nursing homes often exceeds that in hospitals, but reasons for this are not well understood. We sought to measure MRSA burden in a large number of nursing homes and identify facility characteristics associated with high MRSA burden.

Methods: We performed nasal swabs of residents from 26 nursing homes to measure MRSA importation and point prevalence, and estimate transmission. Using nursing home administrative data, we identified facility characteristics associated with MRSA point prevalence and estimated transmission risk in multivariate models.

Results: We obtained 1,649 admission and 2,111 point prevalence swabs. Mean MRSA point prevalence was 24\%, significantly higher than mean MRSA admission prevalence, 16\%, (paired t-test, $p<0.001$ ), with a mean estimated MRSA transmission risk of $16 \%$.

In multivariate models, higher MRSA point prevalence was associated with higher admission prevalence $(p=0.005)$ and higher proportions of residents with indwelling devices $(p=0.01)$. Higher estimated MRSA transmission risk was associated with higher proportions of residents with diabetes $(p=0.01)$ and lower levels of social engagement $(\mathrm{p}=0.03)$.

Conclusions: MRSA importation was a strong predictor of MRSA prevalence, but MRSA burden and transmission were also associated with nursing homes caring for more residents with chronic illnesses or indwelling devices. Frequent social interaction among residents appeared to be protective of MRSA transmission, suggesting that residents healthy enough to engage in group activities do not incur substantial risks of MRSA from social contact. Identifying characteristics of nursing homes at risk for high MRSA burden and transmission may allow facilities to tailor infection control policies and interventions to mitigate MRSA spread.
\end{abstract}

Keywords: MRSA, Healthcare-associated infection, Long-term care, Nursing home

\section{Background}

The burden of methicillin-resistant Staphylococcus aureus (MRSA) in nursing homes is less well studied compared to hospital settings. Nevertheless, MRSA carriage in nursing homes can reach or exceed $50 \%$ of residents [1-8], often surpassing that found in general

\footnotetext{
* Correspondence: courtner@uci.edu

'Division of Infectious Diseases and Health Policy Research Institute,

University of California Irvine School of Medicine, Irvine, USA

Full list of author information is available at the end of the article
}

hospital wards (6-12\%) [9-11] and in intensive care units (7-24\%) [12-16].

Predictors of high MRSA burden in nursing homes are not known, but are likely to include factors that predict acquisition in other healthcare settings, such as diabetes, skin breaks, dialysis, and the presence of indwelling devices [3,17-19]. In addition, nursing homes may have unique risk factors vs. hospitals. Social interaction between residents distinguishes nursing homes from acute care settings, and has an unknown impact upon MRSA acquisition. In turn, factors that influence a resident's ability to socialize-including acuity level and

\section{Biomed Central}


mobility-may influence their risk of acquiring MRSA. Furthermore, facility-level characteristics may influence individual risk, especially for contagious pathogens such as MRSA [20,21]. Residing in a nursing home where most residents are at high risk for MRSA may increase the likelihood of acquisition even for residents who lack these specific risk factors. Elucidating facility characteristics associated with high MRSA burden may be helpful in identifying nursing homes that would benefit from intervention.

We sought to measure MRSA burden in a large number of nursing homes within a single metropolitan county and to identify facility characteristics associated with elevated MRSA burden and transmission.

\section{Methods}

\section{Screening nursing home residents for MRSA}

We measured MRSA carriage among nursing home residents in a convenience sample of 26 of the 72 nursing homes in Orange County, California from October 2008-May 2011. In each nursing home, a point prevalence screening was performed of the bilateral nares of up to 100 residents. In addition, we performed an admission prevalence screening of up to 100 consecutive residents within 3 days of admission. For nursing homes with low bed turnover, a lesser number of residents were screened (30-50), and for nursing homes with an average length of stay in years, admission screening was not performed. For each swabbed resident, we recorded the nursing home day of swab collection, whether there was a known history of MRSA, and whether the resident shared a room.

Bilateral nares swabs (BBL Culture Swabs, Sparks, Maryland) were transported to a central microbiology laboratory and plated within 12 hours. Samples were cultured onto 5\% sheep blood agar (BBL) and selective and differential chromogenic media for MRSA, Spectra MRSA (Remel, Lenexa, Kansas) and incubated for 24 hours. MRSA was identified using Spectra MRSA and confirmed agglutination testing and Gram stain. The Institutional Review Board of the University of California Regents approved this study. This study was completed as a quality improvement project through participating nursing homes and consequently explicit consent was not obtained. However, residents were able to refuse to participate.

\section{Nursing home variables}

Nursing home characteristics were obtained from the Minimum Data Set (MDS), version 2.0 [22]. MDS is an individual resident-level dataset containing assessments of physical, psychological and psycho-social functioning mandated for all residents of Medicare and Medicaid licensed nursing homes in the United States. While we did not obtain data from direct interviews with patients, MDS data has been extensively used in long-term care research and has been validated to measure outcomes such as depression, aggressive behavior and social engagement [23-25]. We calculated the proportion of nursing home residents with various MDS characteristics based upon 2009 data, which represented the most recently available data at the time of our analysis. Variables included facility characteristics such as volume and turnover, as well as the percent of residents with various demographics, comorbidities, and social engagement scores. We used a previously validated social engagement score calculated from MDS data that measures how readily residents interact with others and how willing they are to initiate and participate in activities [25]. The average number of daily direct care hours for nursing staff, average resource utilization group scores (RUGS), and average activities of daily living scores (ADLS) were obtained from Long Term Care Focus [26] for 2007, the most recent year available. RUGS is a facility-level score that reflects the average level of care required by residents, based upon residents' comorbidities, dependence upon caregivers, and required amount of physical and occupation therapy. The RUGS, ADLS and social engagement scores were used as measures of resident functional status.

\section{Analysis}

Admission prevalence was calculated as the percent of residents swabbed upon nursing home admission that were found to be MRSA carriers. Point prevalence was calculated as the percent of patients found to be MRSA carriers when swabbing a representative sample of nursing home residents on a given day. We performed paired t-tests comparing MRSA admission vs. point prevalence and compared nursing home length-of-stay (LOS) for MRSA-positive vs. MRSA-negative residents, since higher LOS for MRSA-positive residents could contribute to higher MRSA prevalence over time. Finally, for nursing homes with both MRSA admission and point prevalence measures, we calculated an estimated facilityspecific transmission risk based upon the difference in percentages between admission and point prevalence divided by the percent of residents that were admitted without MRSA.

We tested associations of facility-level characteristics with nursing home MRSA point prevalence and estimated transmission risk. Variables with $\mathrm{p}<0.1$ on bivariate testing using linear regression models were entered into a multivariate facility-level linear regression model and retained at alpha $=0.05$. A maximum of two facility-level variables per outcome were permitted in each multivariate model to prevent overfitting of the model due to sample size (26 total facilities). All 
variables and outcomes were continuous, except for MRSA admission prevalence and RUGS, which were dichotomized into high vs. low groups based upon median values.

\section{Results}

We obtained 1,649 admission and 2,111 point prevalence swabs from 26 Orange County nursing homes. Of admission swabs, 269 were MRSA positive, while 571 point prevalence swabs were MRSA positive. We were unable to obtain admission prevalence swabs from 7 facilities, due to small facility size and minimal resident turnover. Less than $5 \%$ of residents refused to be swabbed. Facility characteristics are listed in Table 1. Across all nursing homes, mean MRSA admission prevalence was $16 \%$ (standard deviation (SD) 8), while mean
MRSA point prevalence was 24\% (SD 13) (Table 2). Overall, mean MRSA point prevalence was significantly higher than mean MRSA admission prevalence (paired t-test, $\mathrm{p}<0.001)$ despite similar nursing home length-ofstay among MRSA-positive and MRSA-negative residents (399 vs. 436 days; t-test, $\mathrm{p}=0.26$ ). Although overall MRSA point prevalence was significantly higher than admission prevalence, these measures were highly correlated (Pearson coefficient $=0.77$ ). Nevertheless, it was noteworthy that some facilities had nearly equal admission prevalences, but substantially different point prevalences (Table 2). For example, nursing homes 5 and 6 admit 10\% and 11\% MRSA carriers, respectively. However, MRSA point prevalence is $25 \%$ at nursing home 5 , while point prevalence remains stable in nursing home 6 , at $7 \%$.

Table 1 Characteristics of 26 Nursing Homes in Orange County, California

\begin{tabular}{|c|c|c|}
\hline Nursing Home Characteristic & Median (Range) & Mean (Standard Deviation) \\
\hline Number of Beds & $99(24-255)$ & $110(58)$ \\
\hline Median Length of Stay (days) & $102(25-753)$ & $149(189)$ \\
\hline Annual Admissions & $262(18-1526)$ & $421(425)$ \\
\hline \% Annual Resident Turnover & $15 \%(1-70)$ & $19 \%(14)$ \\
\hline Average Direct Care Nursing Staff Hours (per resident day) & $3.5(1.9-7.8)$ & $3.9(1.4)$ \\
\hline \multicolumn{3}{|c|}{ Demographics (as\% of all facility residents) } \\
\hline \multicolumn{3}{|l|}{ Age } \\
\hline$\%<65$ years old & $28(0-86)$ & $30(28)$ \\
\hline$\% 65-<85$ years old & $44(9-57)$ & $40(13)$ \\
\hline$\%>85$ years old & $25(2-72)$ & $30(20)$ \\
\hline$\%$ Male & $43(21-67)$ & $42(12)$ \\
\hline \multicolumn{3}{|l|}{ Race and Ethnicity } \\
\hline$\%$ White & $84(12-99)$ & $81(17)$ \\
\hline$\%$ Black & $1(0-9)$ & $3(3)$ \\
\hline$\%$ American Indian/Alaskan Native & $0(0-2)$ & $0(1)$ \\
\hline$\%$ Asian/Pacific Islander & $12(0-88)$ & $15(18)$ \\
\hline$\%$ Any Non-White & $16(1-88)$ & $18(17)$ \\
\hline \% Hispanic Ethnicity & $14(1-38)$ & $15(15)$ \\
\hline \% Less than High School Education & $24(0-64)$ & $23(17)$ \\
\hline$\%$ Medicare Insurance & $18(1-44)$ & $17(9)$ \\
\hline$\%$ Admitted from Acute Hospital & $82(15-98)$ & $71(29)$ \\
\hline \multicolumn{3}{|c|}{ Comorbidities (as\% of all facility residents) } \\
\hline \% Diabetes & $27(11-59)$ & $31(13)$ \\
\hline \% Skin Lesions & $72(4-100)$ & $67(23)$ \\
\hline \% Fecal Incontinence & $44(5-91)$ & $43(23)$ \\
\hline \% Indwelling Devices & $2(0-46)$ & $12(22)$ \\
\hline$\%$ History of MRSA & $11(0-69)$ & $13(14)$ \\
\hline \multicolumn{3}{|c|}{ Functional Status (average score among all facility residents) } \\
\hline Average Activities of Daily Living Score & $19.82(10.77-26.90)$ & $19.74(3.60)$ \\
\hline Average Resource Utilization Group Score & $0.92(0.81-1.43)$ & $1.0(0.2)$ \\
\hline Average Social Engagement Score & $2(0-4)$ & $2(1)$ \\
\hline
\end{tabular}


Table 2 MRSA Prevalence and Transmission Risk for 26 Nursing Homes

\begin{tabular}{|c|c|c|c|c|}
\hline & No. Beds & $\begin{array}{l}\text { MRSA Admission } \\
\text { Prevalence }^{\mathrm{a}}\end{array}$ & $\begin{array}{l}\text { MRSA Point } \\
\text { Prevalence }\end{array}$ & $\begin{array}{l}\text { Estimated MRSA } \\
\text { Transmission Risk }^{\mathrm{b}}\end{array}$ \\
\hline $\mathrm{NH} 1$ & 124 & $3 \%(3)$ & $8 \%(8)$ & $5 \%$ \\
\hline $\mathrm{NH} 2$ & 59 & $4 \%(2)$ & $22 \%(22)$ & $19 \%$ \\
\hline $\mathrm{NH} 3$ & 145 & $8 \%(8)$ & $30 \%(30)$ & $24 \%$ \\
\hline $\mathrm{NH} 4$ & 208 & $9 \%(9)$ & $19 \%(19)$ & $11 \%$ \\
\hline $\mathrm{NH} 5$ & 137 & $10 \%(5)$ & $25 \%(17)$ & $16 \%$ \\
\hline $\mathrm{NH} 6$ & 24 & $11 \%(11)$ & $7 \%(7)$ & $0 \%$ \\
\hline $\mathrm{NH7}$ & 198 & $12 \%(12)$ & $22 \%(22)$ & $11 \%$ \\
\hline $\mathrm{NH} 8$ & 80 & $13 \%(13)$ & $25 \%(25)$ & $14 \%$ \\
\hline $\mathrm{NH} 9$ & 99 & $14 \%(7)$ & $27 \%(27)$ & $15 \%$ \\
\hline $\mathrm{NH} 10$ & 99 & $16 \%(16)$ & $31 \%(31)$ & $18 \%$ \\
\hline $\mathrm{NH} 11$ & 99 & $16 \%(16)$ & $37 \%$ (37) & $25 \%$ \\
\hline $\mathrm{NH} 12$ & 98 & $16 \%(16)$ & $39 \%(29)$ & $27 \%$ \\
\hline$\overline{\mathrm{NH} 13}$ & 255 & $20 \%(20)$ & $42 \%(42)$ & $28 \%$ \\
\hline $\mathrm{NH} 14$ & 99 & $21 \%(21)$ & $16 \%(16)$ & $0 \%$ \\
\hline $\mathrm{NH} 15$ & 145 & $22 \%(11)$ & $34 \%(34)$ & $15 \%$ \\
\hline $\mathrm{NH} 16$ & 138 & $22 \%(22)$ & $30 \%(30)$ & $10 \%$ \\
\hline $\mathrm{NH} 17$ & 182 & $25 \%(25)$ & $39 \%(39)$ & $19 \%$ \\
\hline $\mathrm{NH} 18$ & 99 & $29 \%(29)$ & $44 \%(44)$ & $21 \%$ \\
\hline $\mathrm{NH} 19$ & 143 & $31 \%(31)$ & $52 \%(52)$ & $30 \%$ \\
\hline $\mathrm{NH} 2 \mathrm{O}$ & 46 & -— & $0 \%(0)$ & $\mathrm{n} / \mathrm{a}$ \\
\hline $\mathrm{NH} 21$ & 124 & -—- & $2 \%(1)$ & $n / a$ \\
\hline $\mathrm{NH} 22$ & 45 & -—- & $10 \%(4)$ & $n / a$ \\
\hline $\mathrm{NH} 23$ & 41 & -—- & $16 \%(4)$ & $n / a$ \\
\hline $\mathrm{NH} 24$ & 99 & -—- & $26 \%(13)$ & $n / a$ \\
\hline $\mathrm{NH} 25$ & 30 & -- & $27 \%(8)$ & $\mathrm{n} / \mathrm{a}$ \\
\hline $\mathrm{NH} 26$ & 46 & -—- & $28 \%(10)$ & $n / a$ \\
\hline Mean (SD) & $110(58)$ & $16 \%(8)$ & $25 \%(13)$ & $16 \%(8)$ \\
\hline Median (range) & 99 (24-255) & $16 \%(3-31)$ & $26 \%(0-52)$ & $15 \%(0-30)$ \\
\hline
\end{tabular}

${ }^{a}$ Admission prevalence swabs were not collected for nursing homes 20 through 26 due to small facility size and minimal resident turnover.

${ }^{\mathrm{b}}$ Estimated transmission risk was calculated as the absolute difference (MRSA point - admission prevalence) divided by the number of at risk patients per 100 admitted. For example, for $\mathrm{NH} 3$, transmission risk $=(30 \%-8 \%) /(100-8)=24 \%$.

In bivariate models (Table 3), MRSA point prevalence was associated $(\mathrm{p}<0.1)$ with annual admissions, MRSA admission prevalence, the percent of residents admitted from acute care hospitals, and the percent of residents with select comorbidities (diabetes, indwelling devices, skin lesions, fecal incontinence). Results for continuous variables are reported per $10 \%$ increase; for example, a $10 \%$ absolute increase in the percent of residents with diabetes was associated with a $7.2 \%$ absolute increase in MRSA point prevalence.

Similar variables were found to be associated $(\mathrm{p}<0.1)$ in bivariate models predicting MRSA transmission risk, including resident turnover rate, the percent of residents $>85$, and percent of residents with diabetes or fecal incontinence. MRSA transmission risk was also associated with the percent of residents who were Hispanic, or had less than a high school education. Facility social engagement scores were negatively associated with MRSA transmission risk. Results for continuous variables are reported per $10 \%$ increase; for example, a $10 \%$ absolute increase in the resident turnover rate was associated with a $2.7 \%$ absolute decrease in MRSA transmission risk.

In multivariate models (Table 4), higher MRSA point prevalence was associated with higher MRSA admission prevalence and a higher percent of residents with indwelling devices. In this model, the percent of residents with indwelling devices and with fecal incontinence were interchangeable. MRSA transmission risk was associated with the percent of residents with diabetes and was negatively associated with social engagement level among residents. In our transmission model, the percent of residents with diabetes and with less than a high school education were interchangeable. 
Table 3 Bivariate Analysis of Factors Associated with Nursing Home MRSA Point Prevalence and MRSA Transmission Risk

\begin{tabular}{|c|c|c|c|c|}
\hline Variable & $\begin{array}{l}\text { Absolute } \% \text { Change MRSA } \\
\text { Point Prevalence per } 10 \% \\
\text { change in variable }\end{array}$ & p-value & $\begin{array}{l}\text { Absolute } \% \text { Change MRSA } \\
\text { Transmission per } 10 \% \\
\text { change in variable }\end{array}$ & p-value \\
\hline \multicolumn{5}{|l|}{ Nursing Home Characteristic } \\
\hline Annual Admissions (per100 admissions) & 1.02 & 0.09 & 0.6 & 0.24 \\
\hline Annual Resident Turnover & -5.9 & $<0.001$ & -2.7 & 0.06 \\
\hline $\begin{array}{l}\text { Average Direct Care Nursing Staff Hours } \\
\text { (per resident day) }\end{array}$ & 1.8 & 0.92 & -0.2 & 0.99 \\
\hline High MRSA Admission Prevalence ${ }^{a}$ & 14.3 & $<0.001$ & 5.6 & 0.18 \\
\hline \multicolumn{5}{|l|}{ Demographics (as\% of all facility residents) } \\
\hline Age under 65 & -1.4 & 0.14 & 0.7 & 0.48 \\
\hline Age over 85 & 0.4 & 0.76 & -1.9 & 0.09 \\
\hline Male Gender & -1.4 & 0.52 & 2.9 & 0.16 \\
\hline Hispanic Ethnicity & 2.9 & 0.21 & 3.1 & 0.05 \\
\hline Non-White Race & 1.5 & 0.33 & 1.6 & 0.11 \\
\hline Education less than High School & 2.6 & 0.1 & 2.3 & 0.03 \\
\hline Admitted from Acute Hospital & 2.4 & 0.006 & 0.4 & 0.71 \\
\hline \multicolumn{5}{|l|}{ Comorbidities (as\% of all facility residents) } \\
\hline Diabetes & 6.9 & $<0.001$ & 3.6 & 0.01 \\
\hline Skin Lesions & 2.2 & 0.05 & -1.0 & 0.41 \\
\hline Fecal Incontinence & 3.5 & 0.001 & 2.2 & 0.03 \\
\hline Indwelling Devices & 2.0 & 0.09 & 1.9 & 0.14 \\
\hline History of MRSA & 3.2 & 0.10 & 2.8 & 0.38 \\
\hline \multicolumn{5}{|l|}{ Functional Status } \\
\hline High Resource Utilization Group ${ }^{a}$ & 4.5 & 0.25 & 1.2 & 0.76 \\
\hline$\%$ Residents with High Social Engagement Score & -2.1 & 0.19 & -2.0 & 0.06 \\
\hline
\end{tabular}

${ }^{\mathrm{a} M R S A}$ admission prevalence and Resource utilization group (RUGS) score were dichotomized into high and low groups around median values.

\section{Discussion}

In comparison to hospitals, the burden and predictors of MRSA in nursing homes are not well understood despite several studies suggesting MRSA prevalence may be much greater in this setting than high risk acute care wards, including intensive care units [12-16]. Nursing homes have a large concentration of high risk patients due to older age, chronic illness, and requirement for sustained nursing care. Nevertheless, the paucity of studies on factors associated with high burden and

Table 4 Multivariate Linear Regression Analysis of Factors Associated with Nursing Home MRSA Point Prevalence and MRSA Transmission Risk

Outcome: Facility MRSA Point Prevalence

\begin{tabular}{|c|c|c|}
\hline Variable & $\begin{array}{l}\text { Absolute Change in MRSA Point Prevalence per absolute increase } \\
\text { of } 10 \% \text { in variable }(95 \% \mathrm{CI})\end{array}$ & p-value \\
\hline High MRSA Admission Prevalence ${ }^{a}$ & $13.0(4.3,21.7)$ & 0.005 \\
\hline \% Residents with Indwelling Device ${ }^{b}$ & $1.8(0.1,3.5)$ & 0.04 \\
\hline \multicolumn{3}{|l|}{ Outcome: Facility MRSA Transmission } \\
\hline Variable & $\begin{array}{l}\text { Absolute Change in MRSA Transmission per absolute increase } \\
\text { of } 10 \% \text { in variable }(95 \% \mathrm{Cl})\end{array}$ & p-value \\
\hline \% Residents with High Social Engagement ${ }^{c}$ & $-2.0(-3.8,-0.2)$ & 0.03 \\
\hline \% Residents with Diabetes ${ }^{d}$ & $3.6(1.1,6.0)$ & 0.01 \\
\hline
\end{tabular}

${ }^{a}$ MRSA admission prevalence was dichotomized at the median value (15\%).

${ }^{b}$ The presence of an indwelling device was collinear with the proportion of residents with fecal incontinence.

c High social engagement score was defined as greater than or equal to 3 out of 6 .

${ }^{d}$ In the transmission model, the percentage of residents with diabetes was collinear with the percent of residents with less than a high school education. 
transmission or prevention may explain why approaches to infection prevention of multi-drug resistant organisms remain non-standardized in nursing homes [7,27-29].

In a large regional survey of nursing homes, we found that MRSA prevalence varied widely, from 0 to over $50 \%$. Unsurprisingly, importation levels were strongly associated with overall prevalence, but, in addition, nursing homes caring for residents with more medical devices had significantly higher MRSA levels. This finding may be directly related to the portals of entry that devices provide for pathogens $[3,18,30,31]$, or it may be reflective of a higher degree of chronic illness in that facility which leads to greater vulnerability for acquisition. Devices have also been associated with MRSA acquisition in hospital-based studies [31,32]. Among nursing homes that admitted similar proportions of residents with MRSA, some nursing homes were able to maintain their overall MRSA burden at or near importation levels, while other nursing homes had overall burden estimates that greatly exceeded importation levels. This suggests that MRSA transmission might be occurring in the latter group and that facilities in the former group may be employing specific strategies to successfully prevent MRSA levels from rising beyond the importation level. Further research is needed to understand whether differences in MRSA burden vs. importation are driven by facility practices, such as infection control policies or environmental cleaning protocols.

Among collected variables, we found that nursing homes with a higher proportion of residents with diabetes had higher estimated MRSA transmission, again suggesting that comorbidities are a marker of vulnerability [33-36]. Surprisingly, a high degree of social engagement among residents was protective of MRSA transmission, suggesting that the level of health needed to engage in activities outweighed the risk of transmission due to social contact. This was reassuring since nursing homes have a responsibility to promote residents' emotional and physical health through social interaction, and this often precludes the adoption of stringent infection control policies found in acute care settings, such as isolation or long-term use of contact precautions.

This study has several limitations. First, we estimated MRSA transmission risk based upon MRSA admission and point prevalence. Second, our prevalence estimates were based upon nasal swabs and not sampling of multiple body sites, and we did not use enrichment techniques for culturing MRSA. As a result, the MRSA prevalences reported here may be an under-estimate of the true burden. Second, we did not collect information on facility practices that may influence MRSA burden, including infection control and environmental practices and frequency of antibiotic use. We also did not collect demographic information on residents who refused to be swabbed; these residents may have been substantially different from participants. However, the refusal rate was less than $5 \%$, suggesting that this small number of non-participants would need to be quite different from participants to change our results. Finally, this is an ecologic study of facility-level characteristics associated with MRSA carriage. More research is needed to understand how facility-level factors influence individual risk of MRSA in this setting. Nevertheless, since infection control and prevention policies are determined on the facility level, facility characteristics may be helpful in identifying nursing homes that should adopt more aggressive strategies (e.g. screening, decolonization, more frequent environmental cleaning) to reduce MRSA burden and transmission.

\section{Conclusions}

In a large, diverse metropolitan county, we found that MRSA burden varied substantially and was associated with both importation and facility-level indicators of comorbidity. However, we also found that higher levels of social engagement among residents were protective of MRSA transmission, a reassuring finding for the national movement toward increasing the community and homelike environment in nursing homes [37]. Identifying characteristics of nursing homes at risk for high MRSA burden may allow facilities to tailor infection control policies and interventions to mitigate spread of MRSA and other pathogens.

\section{Competing interests}

The authors declare that they have no competing interest.

\section{Authors'contributions}

CRM completed all statistical analyses and drafted the manuscript. VQ and DK participated in data collection and entry and contributed to study design. MW assisted with data entry and analyses. GT and KE processed collected nasal swabs. EP, HM, MC, BYL, DBM and SSH contributed to study design, and $\mathrm{SSH}$ also helped to draft the manuscript. All authors read and approved the final manuscript.

\section{Acknowledgements}

We would like to thank the nursing homes in this study for their participation. This project was funded under Contract No. 2902-005-00331 from the Agency for Healthcare Research and Quality, US Department of Health and Human Services as part of the Developing Evidence to Inform Decisions about Effectiveness (DECIDE) program, and the Institute on Aging at the National Institute of Health [grant 1F30AG039958-01]. The authors of this report are responsible for its content. Statements in the report should not be construed as endorsement by the Agency for Healthcare Research and Quality or the US Department of Health and Human Services.

\section{Author details}

${ }^{1}$ Division of Infectious Diseases and Health Policy Research Institute, University of California Irvine School of Medicine, Irvine, USA. ²Department of Pathology and Laboratory Medicine, University of California Irvine School of Medicine, Irvine, USA. ${ }^{3}$ Epidemiology and Assessment Program, Orange County Health Care Agency, Santa Ana, USA. ${ }^{4}$ Department of Medicine, Epidemiology and Biomedical Informatics, University of Pittsburgh School of 
Medicine and Graduate School of Public Health, Pittsburgh, USA. ${ }^{5}$ Department of Medicine and Health Policy Research Institute, University of California Irvine School of Medicine, Irvine, USA

Received: 9 January 2012 Accepted: 17 October 2012

Published: 24 October 2012

\section{References}

1. Bradley SF, Terpenning MS, Ramsey MA, Zarins LT, Jorgensen KA, Sottile WS, Schaberg DR, Kauffman CA: Methicillin-resistant Staphylococcus aureus: Colonization and Infection in a long-term care facility. Ann Intern Med 1991, 115(6):417-422.

2. Muder RR, Brennen C, Wagener MM, Vickers RM, Rihs JD, Hancock GA Yee YC, Miller JM, Yu VL: Methicillin-resistant staphylococcal colonization and infection in a long-term care facility. Ann Intern Med 1991, 114(2):107-112.

3. Garazi M, Edwards B, Caccavale D, Auerbach C, Wolf-Klein G: Nursing homes as reservoirs of MRSA: myth or reality? J Am Med Dir Assoc 2009, 10(6):414-418.

4. Mody L, Kauffman CA, Donabedian S, Zervos M, Bradley SF: Epidemiology of Staphylococcus aureus colonization in nursing home residents. Clin Inf Diseases 2008, 46:1368-1373.

5. Trick WE, Weinstein RA, DeMarais PL, Kuehnert MJ, Tomaska W, Nathan C, Rice TW, McAllister SK, Carson LA, Jarvis WR: Colonization of Skilled-Care Facility Residents with Antimicrobial-Resistant Pathogens. J Amer Geriatrics Soc 2001, 49:270-276.

6. Furuno JP, Hebden JN, Standjford HC, Perencevich EN, Miller RR, Moore AC, Strauss SM, Harris AD: Prevalence of Methicillin-resistant Staphylococcus aureus and Acinetobacter baumannii in a Long-term Acute Care Facility. Am J Infect Control 2008, 36(7):468-471.

7. Reynolds C, Quan V, Kim D, Peterson E, Dunn J, Whealon M, Terpstra L, Meyers H, Cheung M, Lee B, Huang SS: Methicillin-Resistant Stap hylococcus aureus (MRSA) Carriage in 10 Nursing Homes in Orange County, California. Infect Control Hosp Epidemiol 2011, 32(1):91-93.

8. Kreman T, Hu J, Pottinger J, Herwaldt LA: Survey of Long-term-care Facilities in lowa for Policies and Practices Regarding Residents with Methicillin-Resistant Staphylococcus aureus or Vancomycin-Resistant Enterococci. Infect Control Hosp Epidemiol 2005, 26(10):811-821.

9. Robicsek A, Beaumont JL, Paule SM, Hacek DM, Thomson RB Jr, Kaul KL, King P, Peterson LR: Universal Surveillance for Methicillin-Resistant Staphylococcus aureus in 3 Affiliated Hospitals. Ann Intern Med 2008, 148(6):409-418.

10. Mulhausen $\mathrm{PL}$, Harrell $\amalg$, Weinberger M, Kochersberger GG, Feussner JR: Contrasting Methicillin-Resistant Staphylococcus aureus Colonization in Veterans Affairs and Community Nursing Homes. Am J Med 1996, 100(1):24-31.

11. Lucet JC, Paoletti X, Demontpion C, Degrave M, Vanjak D, Vincent C, Adremont A, Jarlier V, Mentre F, Nicolas-Chanoline MH, Staphylococcus aureus Resistant a la Meticilline en Hospitalisation A Domicile (SARM HAD) Study Group: Carriage of Methicillin-Resistant Staphylococcus aureus in Home Care Settings: Prevalence, Duration, and Transmission to Household Members. Arch Intern Med 2009, 169(15):1372-1378.

12. Huang SS, Rifas-Shiman SL, Warren DK, Fraser VJ, Climo MW, Wong ES, Cosgrove SE, Perl TM, Pottinger JM, Herwaldt LA, Jernigan JA, Tokars JL, Diekema DJ, Hinrichsen VL, Yokoe DS, Platt R: Improving MRSA surveillance and reporting in ICUs. J Infect Dis 2007, 195(3):330-338.

13. Kurup A, Chlebicka N, Tan KY, Chen EX, Oon L, Ling TA, Ling ML, Hong JL: Active Surveillance Testing and Decontamination Strategies in Intensive Care Units to Reduce Methicillin-Resistant Staphylococcus aureus Infections. Am J Infect Control 2010, 38(5):361-367.

14. Honda H, Krauss MJ, Coopersmith CM, Kollef MH, Richmond AM, Fraser VJ, Warren DK: Staphylococcus aureus Nasal Colonization and Subsequent Infection in Intensive Care Unit Patients: Does Methicillin Resistance Matter? Infect Control Hosp Epidemiol 2010, 31(6):584-591.

15. Dang CN, Prasad YDM, Boulton AJM, Jude EB: Methicillin-resistant Staphylococcus aureus in the diabetic foot clinic: a worsening problem. Diabetic Med 2003, 20(2):159-161.

16. Lucet JC, Chevret S, Durand-Zaleski I, Chastang C, Regnier B, Multicenter Study Group: Prevalence and risk factors for carriage of methicillin-resistant Staphylococcus aureus at admission to the intensive care unit: results of a multicenter study. Arch Intern Med 2003, 163(2):181-188.
17. Lederer SR, Riedelsdorf G, Schiffl H: Nasal Carriage of Methicillin-resistant Staphylococcus aureus: the Prevalence, Patients at Risk and the Effect of Elimination on Outcomes Among Outpatient Haemodialysis Patients. Eur J Med Res 2007, 12(7):284-288.

18. Smith PW, Bennett G, Bradley S, Drinka P, Lautenbach E, Marx J, Mody L, Nicolle L, Stevenson K: SHEA/APIC Guideline: Infection Prevention and Control in the Long-Term Care Facility. Infect Control Hosp Epidemiol 2008, 29:785-814.

19. March A, Aschbacher R, Dhanji H, Livermore DM, Bottcher A, Sleghel F, Maggi S, Noale M, Larcher C, Woodford N: Colonization of Residents and Staff of a Long-Term-Care Facility and Adjacent Acute-Care Hospital Geriatric Unit by Multiresistant Bacteria. Clin Microbiol Infect 2010, 16(7):934-944.

20. Robert SA: Community-Level Socioeconomic Status Effects on Adult Health. J Health Soc Behav 1998, 39:18-37.

21. Figueroa JB, Breen N: Significance of Underclass Residence on the Stage of Breast or Cervical Cancer Diagnosis. Am Econ Rev 1995, 85(2):112-116.

22. Research Data Assistance Center. www.resdac.org/MDS/data_available.asp.

23. Hendrix CC, Sakauye KM, Karabatsos G, et al: The use of the Minimum Data Set to identify depression in the elderly. J Am Med Dir Assoc 2003, 4(6):308-312.

24. Perlman CM, Hirdes JP: The aggressive behavior scale: a new scale to measure aggression based on the minimum data set. J Am Geriatr Soc 2008, 56(12):2298-2303.

25. Kiely DK, Flacker JM: The Protective Effect of Social Engagement on 1-year Mortality in a Long-Stay Nursing Home Population. J Clin Epidemiol 2003, 56:472-478.

26. Long Term Care Focus. www.Itcfocus.org

27. Mylotte JM, Karuza J, Bentley DW: Methicillin-Resistant Staphylococcus aureus: A Questionnaire Survey of 75 Long-Term Care Facilities in Western New York. Infect Control Hosp Epidemiol 1992, 13(12):711-718.

28. Hughes C, Smith M, Tunney M: Infection Control Strategies for Preventing the Transmission of Methicillin-resistant Staphylococcus aureus (MRSA) in nursing homes for older people. Cochrane Database Syst Rev 2008, 23(1):CD006354

29. Stevenson KB, Loeb M: Performance improvement in the long-term-care setting: building on the foundation of infection control. Infect Control Hosp Epidemiol 2004, 25(1):72-9.

30. Kutlu SS, Cevahir N, Akalin S, Akin F, Dirgen CS, Bastermir M, Tekin K: Prevalence and Risk Factors for Methicillin-resistant Staphylococcus aureus Colonization in a Diabetic Outpatient Population: a Prospective Cohort Study. Am J Infect Control 2011, epub ahead of print.

31. Huang SS, Datta R, Rifas-Shiman S, Kleinman K, Placzek H, Lankiewicz JD, Platt R Colonization with Antibiotic-Susceptible Strains Protects against MethicillinResistant Staphylococcus aureus but not Vancomycin-Resistant Enterococci Acquisition: A Nested Case-control Study. Crit Care 2011, 15(5):R210.

32. Wibbenmeyer L, Williams I, Ward M, Xiao X, Light T, Latenser B, Lewis $R$, Kealey GP, Herwaldt L: Risk factors for acquiring vancomycin-resistant Enterococcus and methicillin-resistant Staphylococcus aureus on a burn surgery step-down unit. J Burn Care Res 2010, 31(2):269-79.

33. van Velzen EVH, Reilly JS, Kavanagh K, Leanord A, Edwards GF, Girvan EK, Gould IM, Mackenzie FM, Masterton R: A Retrospective Cohort Study into Acquisition of MRSA and Associated Risk Factors after Implementation of Universal Screening in Scottish Hospitals. Infect Control Hosp Epidemiol 2011, 32(9):889-896.

34. Miller R, Esmail H, Peto T, Walker S, Crook D, Wyllie D: Is MRSA admission bacteraemia community-acquired? A case control study. J Infect 2008 56(3):163-170

35. Warren DK, Guth RM, Coopersmith CM, Merz LR, Zack JE, Fraser VJ: Epidemiology of methicillin-resistant Staphylococcus aureus colonization in a surgical intensive care unit. Infect Control Hosp Epidemiol 2006 27(10):1140-1.

36. Moore C, Dhaliwal J, Tong A, Eden S, Wigston C, Willey B, McGeer A Risk factors for methicillin-resistant Staphylococcus aureus (MRSA) acquisition in roommate contacts of patients colonized or infected with MRSA in an acute-care hospital. Infect Control Hosp Epidemiol 2008, 29(7):600-6.

37. Center for Medicare and Medicaid Services: Guidance to Surveyors of Long Term Care Facilities; 2009:100-107.

doi:10.1186/1471-2334-12-269

Cite this article as: Murphy et al:: Nursing home characteristics associated with methicillin-resistant Staphylococcus aureus (MRSA) Burden and Transmission. BMC Infectious Diseases 2012 12:269. 